\title{
A study on how to keep the temperature of water in the bathtub unchanged
}

\author{
Lei $\mathrm{Yu}$ \\ ${ }^{1}$ School of North China Electric Power University, Baoding 071003, China \\ 3023961035@qq.com
}

Keywords: keep the temperature, the bathtub water, the multi-objective programming.

\begin{abstract}
In order to keep the temperature close to the initial temperature and save more water,we use the average temperature of the water in the bathtub as a constant temperature of the bath water ,and obtained the relationship between the flow rate of water and the average temperature of water in the bathtub. In order to optimize the model, the multi-objective programming is converted into a single-objective one with the linear weighted method.we pretreated and standardized the data.Besides, and put different proper weights to the temperature in the bathroom,the temperature in the bathtub and the variance of the temperature. We find that the strategy are different with the change of the weights, but we find that the optimal potential may be the proper water temperature (41 degrees Celsius) and the flow rate of water (14.8milliliter/second)
\end{abstract}

\section{Introduction}

We all like to take a bath in the right temperature of the water, but the bath in the water temperature is constantly under the if not add hot water. However, we often can not find the right hot water flow to maintain the water temperature. Therefore, it is necessary to study the relationship between the flow of hot water and the water temperature.

\section{Organization of the Text}

Table 1: Notations and Descriptions

\begin{tabular}{ll}
\hline Notations & Descriptions \\
\hline Tin & The temperature in the bathtub \\
Tout & The temperature in the bathroom \\
$T_{0}$ & The temperature of hot water flowing out of the tap \\
Vout & the flow rate of water \\
$\delta^{\prime}$ & Thickness of bubble layer \\
$c$ & Specific heat capacity \\
$\rho$ & The dendity of the water \\
$\lambda$ & Heat conductivity of the acrylic sheets \\
$\alpha$ & Heat transfer coefficient between air and water \\
$\delta$ & Thickness of bathtub wall \\
$\sigma^{2}(T)$ & The variance of the temperature in the bathtub \\
$T$ & Evenness of the temperature in the bathtub \\
$p$ & Objective function of the multiple objective \\
\hline
\end{tabular}

In order to make the calculation easier, we simplify the regular shape into rectangle, as 

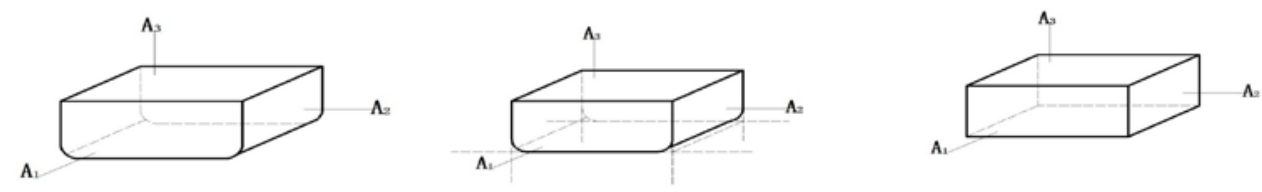

Figure 1:

In order to find the best strategy to keep the temperature as close as possible to the initial temperature without wasting too much water,we analyze the relationship between the temperature in the bathtub and the volume of water overflow from the bathtub per unit time.The basic formula we used are as following :

Fourier's Law

$$
Q=-\lambda \frac{t}{d e n} A
$$

Newton's Law of Cooling

The heat convection $(Q)$ between fluid and wall of bathtub is proportional to the temperature difference between them and the area of the wall(A) :

$$
Q=\partial A\left(\mathrm{t}_{w}-\mathrm{t}_{f}\right)
$$

The sum of the heat radiation of bathtub water in the five direction of the inner wall and the heat radiation between air and water :

$$
Q_{1}=\left(\frac{2 \lambda A_{1}}{\delta}+\frac{2 \lambda A_{2}}{\delta}+\frac{\lambda A_{3}}{\delta}+\partial A_{3}\right)\left(T_{\text {in }}-T_{\text {out }}\right)
$$

The difference between the energy of water overflow from the bathtub per unit time and water flowing into the bathtub from the tap.

Energy Conservation Law

$$
Q_{1}^{\prime}=c \rho V_{\text {out }}\left(\mathrm{T}_{0}-\mathrm{T}_{\text {in }}\right)
$$

$$
\begin{gathered}
Q_{1}^{\prime}=Q_{1} \\
c \rho V_{\text {out }}\left(\mathrm{T}_{0}-\mathrm{T}_{\text {in }}\right)=\left(\frac{2 \lambda A_{1}}{\delta}+\frac{2 \lambda A_{2}}{\delta}+\frac{\lambda A_{3}}{\delta}+\partial A_{3}\right)\left(T_{\text {in }}-T_{\text {out }}\right)
\end{gathered}
$$

equates to :

$$
V_{\text {out }}=\frac{\left(\frac{2 \lambda \mathrm{A}_{1}}{\delta}+\frac{2 \lambda \mathrm{A}_{2}}{\delta}+\frac{\lambda \mathrm{A}_{3}}{\delta}+\partial \mathrm{A}_{3}\right)\left(T_{\text {in }}-T_{\text {out }}\right)}{c \rho\left(\mathrm{T}_{0}-\mathrm{T}_{\text {in }}\right)}
$$

Through analyzing the equation, we find that it is a Multiple Objective Programming problem aiming to determine the best strategy that the temperature of bathtub water as close as possible to the initial without wasting too much water. ${ }^{[1]}$

objective function :

$$
\begin{cases}\max & T_{\text {in }} \\ \min & V_{\text {out }}\end{cases}
$$

constraint condition :

$$
\left\{\begin{array}{l}
V_{\text {out }}=\frac{\left(\frac{2 \lambda A_{1}}{\delta}+\frac{2 \lambda A_{2}}{\delta}+\frac{\lambda A_{3}}{\delta}+\partial A_{3}\right)\left(T_{\text {in }}-T_{\text {out }}\right)}{c \rho\left(\mathrm{T}_{0}-\mathrm{T}_{\text {in }}\right)} \\
37<T_{\text {in }}<45
\end{array}\right.
$$

Simplified Model

In practice, the most comfortable temperature is not same for different people, we limited $T_{i n}$,make taht the maxmium $T_{0}<T_{i n}$,thus, we can find the strategy, and the Multiple Objective Programming can be converted to a Single Objective Linear Programming. Limit the temperature of the bathtub water and optimized waste water.

Limit the temperature of the bathtub water and optimized waste water 


$$
\max T_{\text {in }} \quad s t\left\{\begin{array}{l}
T_{\text {in }}<T_{\text {out }} \\
V_{\text {out }}=\frac{\left(\frac{2 \lambda A_{1}}{\delta}+\frac{2 \lambda A_{2}}{\delta}+\frac{\lambda A_{3}}{\delta}+\partial A_{3}\right)\left(T_{\text {in }}-T_{\text {out }}\right)}{c \rho\left(T_{0}-T_{\text {in }}\right)} \\
37<T_{\text {in }}<45
\end{array}\right.
$$

Limit the waste water and optimized the temperature of bathtub

$$
\min V_{\text {out }} \quad s t\left\{\begin{array}{l}
V_{\text {out }}<V \\
V_{\text {out }}=\frac{\left(\frac{2 \lambda A_{1}}{\delta}+\frac{2 \lambda A_{2}}{\delta}+\frac{\lambda A_{3}}{\delta}+\partial A_{3}\right)\left(T_{\text {in }}-T_{\text {out }}\right)}{c \rho\left(\mathrm{T}_{0}-\mathrm{T}_{\text {in }}\right)} \\
37<T_{\text {in }}<45
\end{array}\right.
$$

Combine the two conditions with weights $S(0<S<1)$ and $(1-S)$,

$$
\min S \quad V_{\text {out }}-(1-S) T_{\text {in }} \quad s t\left\{\begin{array}{l}
V_{\text {out }}=\frac{\left(\frac{2 \lambda A_{1}}{\delta}+\frac{2 \lambda A_{2}}{\delta}+\frac{\lambda A_{3}}{\delta}+\partial A_{3}\right)\left(T_{\text {in }}-T_{\text {out }}\right)}{c \rho\left(\mathrm{T}_{0}-\mathrm{T}_{\text {in }}\right)} \\
37<T_{\text {in }}<45
\end{array}\right.
$$

Table 2: Parameters and Value

\begin{tabular}{|l|l|}
\hline Parameters & Values \\
\hline the area of a surface in the model $\left(A_{1}\right)$ & $2.0 \mathrm{~m} \times 0.8 \mathrm{~m}=1.6 \mathrm{~m}^{2}$ \\
the area of a surface in the model $\left(A_{2}\right)$ & $1.0 \mathrm{~m} \times 0.8 \mathrm{~m}=0.8 \mathrm{~m}^{2}$ \\
the area of a surface in the model $\left(A_{3}\right)$ & $1.0 \mathrm{~m} \times 2.0 \mathrm{~m}=2.0 \mathrm{~m}^{2}$ \\
thermal conductivity of the acrylic sheets & $0.19 \mathrm{~W} /(\mathrm{m} \cdot \circ \mathrm{C})$ \\
thermal transfer coefficient between air and water & $0.024 \mathrm{~W} /\left(\mathrm{m}^{2} \cdot \circ \mathrm{C}\right)$ \\
specific heat capacity of acrylic & $4.2 \times 10^{3} \mathrm{~J} /(\mathrm{kg} \cdot \circ \mathrm{C})$ \\
the dendity of the water & $0.99 \times 10^{3} \mathrm{~kg} / \mathrm{m}^{3}$ \\
thickness of bathtub wall & $0.02 \mathrm{~m}$ \\
the temperature of hot water flowing out of the tap & $45 \circ \mathrm{C}$ \\
the temperature in the bathroom & $25 \circ \mathrm{C}$ \\
\hline
\end{tabular}

To solve the problem quantitatively, we searched for amounts of data about the bathtub. Eventually, we consider the material of the bathtub is acrylic and the data to be used to solve the problem are listed in Table 2

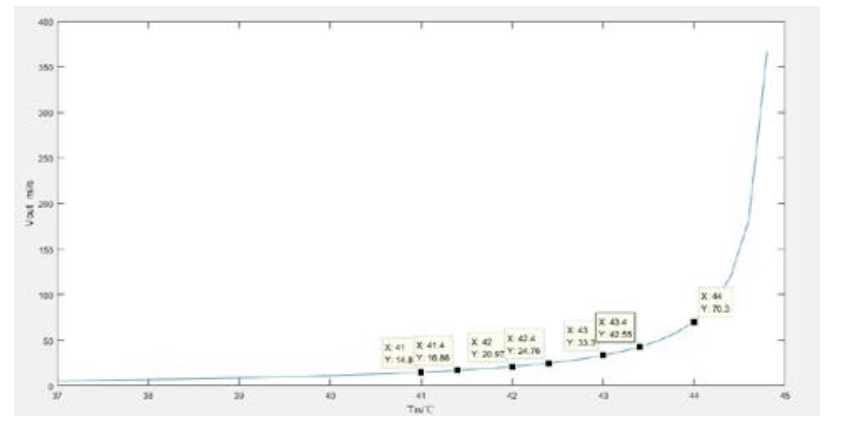

Figure 2: $V_{\text {out }}-T_{\text {in }}$ relationship

The relationship of $V_{\text {out }}$ and $T_{\text {in }}$ shows as Figure 2, we can know that :

1. The $V_{\text {out }}-T_{\text {in }}$ function is an increasing function, which fits practical experience well.

2. When the temperature changes from $43^{\circ} \mathrm{C}$ to $44.8^{\circ} \mathrm{C}$, the growth rate of the wasted water may substantial change. The change during this period are in Table 3

Table 3: $V_{\text {out }}-T_{\text {in }}$ relationship

\begin{tabular}{|c|c|c|c|c|c|c|c|c|c|c|}
\hline Tin & 42.0 & 42.2 & 42.4 & 42.6 & 42.8 & 43.0 & 43.2 & 43.4 & 43.6 & 43.8 \\
\hline Vout & 20.9 & 22.7 & 24.7 & 27.1 & 29.9 & 33.3 & 37.4 & 42.5 & 49.1 & 57.2 \\
\hline
\end{tabular}


We can get that the $V_{\text {out }}-T_{\text {in }}$ curve makes a sudden change when $T_{\text {in }}=43{ }^{\circ} \mathrm{C}$, when $T_{\text {in }}<43{ }^{\circ} \mathrm{C}$, although $T_{\text {in }}$ rapidly increase, $V_{\text {out }}$ growth slowly, when $T_{\text {in }}>43^{\circ} \mathrm{C}$, it will have the opposite situation.

Considering that the temperature distribution is a factor that we can not ignorethus the results of the model need to be further optimized.Linear weighting method can be used to sovle this problem,

Data Normalization

Table 4:

\begin{tabular}{|l|l|l|l|l|l|l|l|l|}
\hline Tin & 37 & 38 & 39 & 40 & 41 & 42 & 43 & 44 \\
\hline$\sigma^{2}(T)$ & 0.8508 & 0.9315 & 0.9578 & 1.0600 & 1.6348 & 2.3433 & 2.8770 & 3.0017 \\
\hline Vout & 5.5500 & 6.8714 & 8.6333 & 11.10 & 14.80 & 20.9667 & 33.333 & 70.3333 \\
\hline
\end{tabular}

Table 5:

\begin{tabular}{|l|l|l|l|l|l|l|l|l|}
\hline$\frac{1}{T_{\text {in }}}$ & 0.0270 & 0.0263 & 0.0256 & 0.0250 & 0.0244 & 0.0238 & 0.0233 & 0.0227 \\
\hline
\end{tabular}

Normalization process makeing transform of squence :

$$
y_{i}=\frac{x_{i}-\min _{1 \leq j \leq n} x_{j}}{\max _{1 \leq j \leq n} x_{j}-\min _{1 \leq j \leq n} x_{j}}
$$

Table 6:

\begin{tabular}{|l|l|l|l|l|l|l|l|l|}
\hline Tin & 0.1364 & 0.1328 & 0.1294 & 0.1262 & 0.1231 & 0.1201 & 0.1173 & 0.1147 \\
\hline$\sigma^{2}(T)$ & 0.0623 & 0.0682 & 0.0701 & 0.0776 & 0.1197 & 0.1716 & 0.2107 & 0.2198 \\
\hline Vout & 0.0324 & 0.0401 & 0.0503 & 0.0647 & 0.0863 & 0.1222 & 0.1941 & 0.4099 \\
\hline
\end{tabular}

Object Function Derivation The multi-objective programming is coverted into a singleobjective one with linear weighted method :

$$
\begin{gathered}
p=w_{1} \cdot T_{\text {in }}+w_{2} \cdot V_{\text {out }}+w_{3} \cdot \delta^{2}(T) \\
w_{1}+w_{2}+w_{3}=1
\end{gathered}
$$

Here we consider the weight of the $\mathrm{w} 1>\mathrm{w} 2>\mathrm{w} 3$ value, the results are as follows :

Table 7:

\begin{tabular}{|l|l|l|l|l|l|l|l|l|}
\hline Tin & 37 & 38 & 39 & 40 & 41 & 42 & 43 & 44 \\
\hline$p$ & 0.1265814 & 0.1240856 & 0.1218815 & 0.1202703 & 0.120068 & 0.1213448 & 0.1253641 & 0.1404037 \\
\hline
\end{tabular}

From the above table Table 7 , we get the proper temperature $(41 \circ C)$ and flow rate of water $(14.8 \mathrm{ml} / \mathrm{s})$

\section{Conclusions}

The strategy are different with the change of the weights, but we find that the optimal potential may be the proper water temperature (41 degrees Celsius) and the flow rate of water (14.8milliliter/second)

\section{References}

[1] ShouKui Si XiJing Xun. Mathematical modeling algorithm and application. Beijing: National Defense Industry Press 2015.7

[2] http://wenku.baidu.com/view/9a2c5fcd050876323112129b.h/

[3] http://wenku.baidu.com/view/b90f7aee19e8b8f67c1cb98a.html/

[4] http://wenku.baidu.com/view/05a8a011866fb84ae45c8de6.h/

[5] http://baike.haosou.com/doc/2531035.html/ 